Study protocol

\title{
An action research protocol to strengthen system-wide inter-professional learning and practice [LP07755 I 4]
} Jeffrey Braithwaite*1,2, Johanna I Westbrook ${ }^{3}$, A Ruth Foxwell4, Rosalie Boyce ${ }^{5}$, Timothy Devinney ${ }^{6}$, Marc Budge ${ }^{7}$, Karen Murphy ${ }^{8}$, MaryAnn Ryall ${ }^{9}$, Jenny Beutel ${ }^{10}$, Rebecca Vanderheide ${ }^{11}$, Elizabeth Renton ${ }^{12}$, Joanne Travaglia1,2, Judy Stone ${ }^{8}$, Amanda Barnard7, David Greenfield ${ }^{1,2}$, Angus Corbett ${ }^{13}$, Peter Nugus ${ }^{1,2}$ and Robyn Clay-Williams ${ }^{1,2}$

\begin{abstract}
Address: ${ }^{1}$ Centre for Clinical Governance Research, Faculty of Medicine, University of New South Wales, 10 Arthur St, Kensington, NSW 2052, Australia, ${ }^{2}$ School of Public Health and Community Medicine, Faculty of Medicine, University of New South Wales, Samuels Building, Kensington, NSW 2052, Australia, ${ }^{3}$ Health Informatics Research \& Evaluation Unit, Faculty of Health Sciences, The University of Sydney, 75 East St Lidcombe, NSW 1825, Australia, ${ }^{4}$ University of Canberra, ACT 2601, Australia, ${ }^{5}$ School of Health \& Rehabilitation Sciences, The University of Queensland, St Lucia, Queensland 4072, Australia, ${ }^{6}$ Australian Graduate School of Management, University of New South Wales, Sydney NSW 2052, Australia, ${ }^{7}$ ANU Medical School, The Australian National University, C/- The Canberra Hospital, PO Box 11, ACT 2606, Australia, ${ }^{8}$ ACT Health, Allied Health Adviser's Office, Level 2, 11 Moore Street, Canberra City, ACT, Australia, ${ }^{9}$ ACT Health, c/- 11 Moore St Canberra City, ACT, Australia, ${ }^{10}$ Department of Health, CitiCentre Building, 11 Hindmarsh Square, Adelaide South Australia, 5000, Australia, ${ }^{11}$ School of Health Sciences - Nursing, University of Canberra, Canberra, ACT 2601, Australia, ${ }^{12}$ The Canberra Hospital, PO Box 11, ACT 2606, Australia and ${ }^{13}$ Faculty of Law, University of New South Wales, Sydney, NSW 2052, Australia
\end{abstract}

Email: Jeffrey Braithwaite* - j.braithwaite@unsw.edu.au; Johanna I Westbrook - j.westbrook@usyd.edu.au; A

Ruth Foxwell - ruth.foxwell@canberra.edu.au; Rosalie Boyce - r.boyce@uq.edu.au; Timothy Devinney - t.devinney@agsm.edu.au; Marc Budge - marc.budge@anu.edu.au; Karen Murphy - Karen.Murphy@act.gov.au; Mary-Ann Ryall - mary-ann.ryall@anu.edu.au; Jenny Beutel - jenny.beutel@health.sa.gov.au; Rebecca Vanderheide - Rebecca.Vanderheide@canberra.edu.au;

Elizabeth Renton - Elizabeth.Renton@act.gov.au; Joanne Travaglia - j.travaglia@unsw.edu.au; Judy Stone - Judy.Stone@act.gov.au; Amanda Barnard - amanda.barnard@anu.edu.au; David Greenfield - d.greenfield@unsw.edu.au; Angus Corbett - a.corbett@unsw.edu.au; Peter Nugus - p.nugus@student.unsw.edu.au; Robyn Clay-Williams - r.clay-williams@aanet.com.au

* Corresponding author

Published: 13 September 2007

BMC Health Services Research 2007, 7:144 doi:10.1186/1472-6963-7-144
Received: 6 July 2007

Accepted: 13 September 2007

This article is available from: http://www.biomedcentral.com//472-6963/7//44

(C) 2007 Braithwaite et al; licensee BioMed Central Ltd.

This is an Open Access article distributed under the terms of the Creative Commons Attribution License (http://creativecommons.org/licenses/by/2.0), which permits unrestricted use, distribution, and reproduction in any medium, provided the original work is properly cited.

\begin{abstract}
Background: Inter-professional learning (IPL) and inter-professional practice (IPP) are thought to be critical determinants of effective care, improved quality and safety and enhanced provider morale, yet few empirical studies have demonstrated this. Whole-of-system research is even less prevalent. We aim to provide a four year, multi-method, multi-collaborator action research program of IPL and IPP in defined, bounded health and education systems located in the Australian Capital Territory (ACT). The project is funded by the Australian Research Council under its industry Linkage Program.

Methods/Design: The program of research will examine in four inter-related, prospective studies, progress with IPL and IPP across tertiary education providers, professional education, regulatory and registration bodies, the ACT health system's streams of care activities and teams, units and wards of the provider facilities of the ACT health system. One key focus will be on pushpull mechanisms, ie, how the education sector creates student-enabled IPP and the health sector
\end{abstract}


demands IPL-oriented practitioners. The studies will examine four research aims and meet 20 research project objectives in a comprehensive evaluation of ongoing progress with IPL and IPP.

Discussion: IPP and IPL are said to be cornerstones of health system reforms. We will measure progress across an entire health system and the clinical and professional education systems that feed into it. The value of multi-methods, partnership research and a bi-directional push-pull model of IPL and IPP will be tested. Widespread dissemination of results to practitioners, policymakers, managers and researchers will be a key project goal.

\section{Background Introduction}

Industries as diverse as health [1,2], aviation [3], manufacturing [4], finance [5], education [6] and the military [7] have identified that collaborative learning and teambased practices are key drivers of performance improvement, safer organisations and systems renewal. Yet there is limited research which demonstrates convincing models of inter-professional learning (IPL) (also titled inter-professional education, IPE) and inter-professional practice (IPP) that successfully achieve these outcomes, particularly across whole health systems. This is a substantial issue requiring attention.

This project's broad goal is to use IPL as the basis for improving IPP, which in turn is thought to lead to enhanced safety and quality of care for patients, and morale and outcomes for patients, staff and students $[8,9]$, across an entire health system. This means the project stands at the intersection of three industries - tertiary education, professionally-based education, and the health system, and it spans both the public and private heath sectors. Specifically, the project will achieve its overarching goal through an Australian Research Council (ARC) funded action research project to strengthen IPL and IPP across the Australian Capital Territory (ACT) health and tertiary and professional education systems.

By action research we mean disseminating findings to participants and other stakeholders, encouraging bi-directional feedback and enabling reflection to stimulate productive change and improvement in a participatory environment. The scientific innovation we aim to realise is to enhance systems-wide teamwork and collaboration through the application and testing of a new model of IPL and IPP in order to bring about profound culture change in the way health professionals work together to deliver services. The project contributes the largest, most comprehensive effort to achieve this yet attempted. We define IPL as "a collaborative, interdisciplinary education and learning process designed to produce effective, multidisciplinary patient centred care" [10] and IPP is the enactment of competencies required to attain this [11]. IPL involves educating clinical professional staff (doctors, nurses and midwives, and allied health practitioners) in multidisci- plinary approaches with the aim of encouraging IPP - ie, greater levels of teamwork, collaboration, knowledgesharing and problem-solving in health settings.

\section{The significance of IPL and IPP}

Why are IPL and IPP important; how will they contribute to improvements? Why is this project significant? Previous studies, reviews and commentaries have suggested that IPL can lead to collaborative IPP amongst clinicians and clinical groups [12,13]. This, in turn, is believed to contribute to safer and higher quality services to patients, and improved morale for staff and students $[14,15]$. The literature suggests that patient care (or, outside of health care, services to customers more generally) will be improved by stronger practitioner relationships, teamwork and inter-professional communication.

Summarising this claim, we have argued that "IPL is centrally concerned with improving the way people work together so that clinicians can grow professionally, learn from others, provide support to colleagues and improve the quality of care to patients" [16]. The putative benefits of IPL and IPP have been well documented: enhanced communication and trust amongst clinical groups [17], collaborative skills [18], reductions in between-professional rivalries [19], and better professional relationships [20]. IPL is held to build team approaches [21], and lead to more creative, integrated services [22]. IPL is said to help students understand how to contribute effectively with other disciplines [23]. Establishing common educational curricula across health professional groups will logically help create common philosophies, languages, perspectives and values [24] and enable skills transfers across the professional silos that prevail today [25].

However, there have been criticisms to balance these optimistic assessments. Progress to date has been slow and uneven. Some tertiary education providers have been uncomfortable about IPL. Existing professionally-based educational structures and practices facilitate specialisation, and maintain medical, nursing and allied health traditions and unique contributions, albeit at the expense of teamwork [26]. Others have argued that IPL and IPP can be riven with unclear philosophies, replete with muddled thinking and multiple objectives [27], and they might 
often have more theoretical potential than actual importance [28]. The sharpest criticism comes from those who argue that IPL and IPP advocates have failed to provide strong evidence for their claims. The data supporting the proposition that IPL influences IPP to create sustained systems change is weak and diffuse, and the evidence largely comprises non-transferable case study, survey and other limited data $[29,30]$. There is no level 1 , randomised study showing convincingly that IPL has worked; but neither is there strong level 1 evidence showing that it does not $[31,32]$. Deeper, more extensive evaluation efforts are therefore required and action research demonstrations of IPL and IPP are needed. Ideally, we would study an entire health system in a project that involved multi-methods and multiple levels; it is time to do so.

The action research project we propose addresses this crucial problem. It is hard to overestimate its importance. Health is an exemplar industry requiring effective teamwork: whenever things go wrong in health care, reports [33], enquiries [34] and studies [35] show that a predetermining factor is that patient care is delivered in a fragmented, isolated way, with health-care professionals having failed to collaborate effectively. Safety is compromised and quality suffers in such circumstances [36]. Internationally, the rate of adverse events - incidents which harm patients, caused by the health care system itself - is estimated to occur in $10 \%$ of all admissions [37]. It is well established that in the order of 18,000 Australian patients die and 50,000 patients are disabled annually and major causes include poor communication and lack of teamwork as well as tribal, non-collaborative structures [38]. IPL and IPP are thus argued to be crucial underlying determinants of safer acute care models and improved quality of services.

\section{The case for the project}

There is a growing understanding amongst policymakers, educators and clinicians that IPL's contribution, and the enactment of IPP, are important but as yet unrealised. For example, the Health Workforce Advisory Committee of the New Zealand Government has argued: "Health practitioners must learn to work in teams whose aim is to provide safe, high-quality, integrated and well-managed care that makes best use, in the widest sense, of all the resources a community has to commit to health .... To achieve this will require changes to the way health practitioners are trained and deployed, and to the way they work" [39]. The Institute of Medicine (IOM) in the United States of America put it this way: "Clinical education simply has not kept pace with or been responsive enough to shifting patient demographics and desires, changing health system expectations, evolving practice requirements and staffing arrangements, new information, a focus on improving quality, or new technologies .... Once in practice, health professionals are asked to work in interdisciplinary teams, often to support those with chronic conditions, yet they are not educated together or trained in team-based skills" [40]. Canada's Commission on the Future of Health Care agrees: "If health care providers are expected to work together and share expertise in a team environment, it makes sense that their education and training should prepare them for this type of working arrangement" [41]. The National Health Service (NHS) in the United Kingdom has expressed a confirming view: "All health professionals should expect their education and training to include common learning with other professions" [42].

Quite simply, however, regardless of the favourable admonitions, no one has put a research team in the field under the right conditions (with receptive research partners, a health and related education system with a strong readiness to engage and a motivated and skilled workforce) to do this work, despite the widespread international agreement about the imperative for systems-wide IPL and IPP. We conducted a literature review on IPL and IPP [10] in preparation for the partnership's work together in 2005 and to design this project. This has helped position ACT Health and the partners and has laid the platform for IPL and IPP across the Territory. We uncovered 37,812 references. We subjected these primary references to a content analysis using Leximancer, a software analysis tool to create a conceptual map of IPL and IPP. We conducted a secondary refining process and excluded nonsubstantial, atheoretical, non-empirical and less relevant articles. The usable literature set comprised 3,765 references which were reviewed by two independent researchers, sorted into categories and further synthesised. We found no previous study of the kind we are describing here, internationally or locally. In as rigorous a way as is possible therefore we will be advancing the knowledge base in this area.

\section{Methods/Design \\ Collaborators}

We aim to produce an action research demonstration and conduct an extensive formative and summative evaluation of IPL and IPP through a project in which we work collaboratively in a team-based, researcher-industry partnership to assess four components of IPL (Figure 1) over a four year enactment period. The Centre for Clinical Governance Research (CCGR) at University of New South Wales (UNSW) provides research leadership to the project. ACT Health is a public health system of 5,683 people $(4,869$ full-time equivalent staff, FTE) at February 2006 , providing 417,186 episodes of inpatient care in 2004-2005 as well as 427,685 community health and 226,908 community mental health occasions of service. It has a budget of $\$ 671.3$ million. It is embarking in concert with project partners on a large-scale, comprehensive, longitudinal process of attempting to influence and institu- 


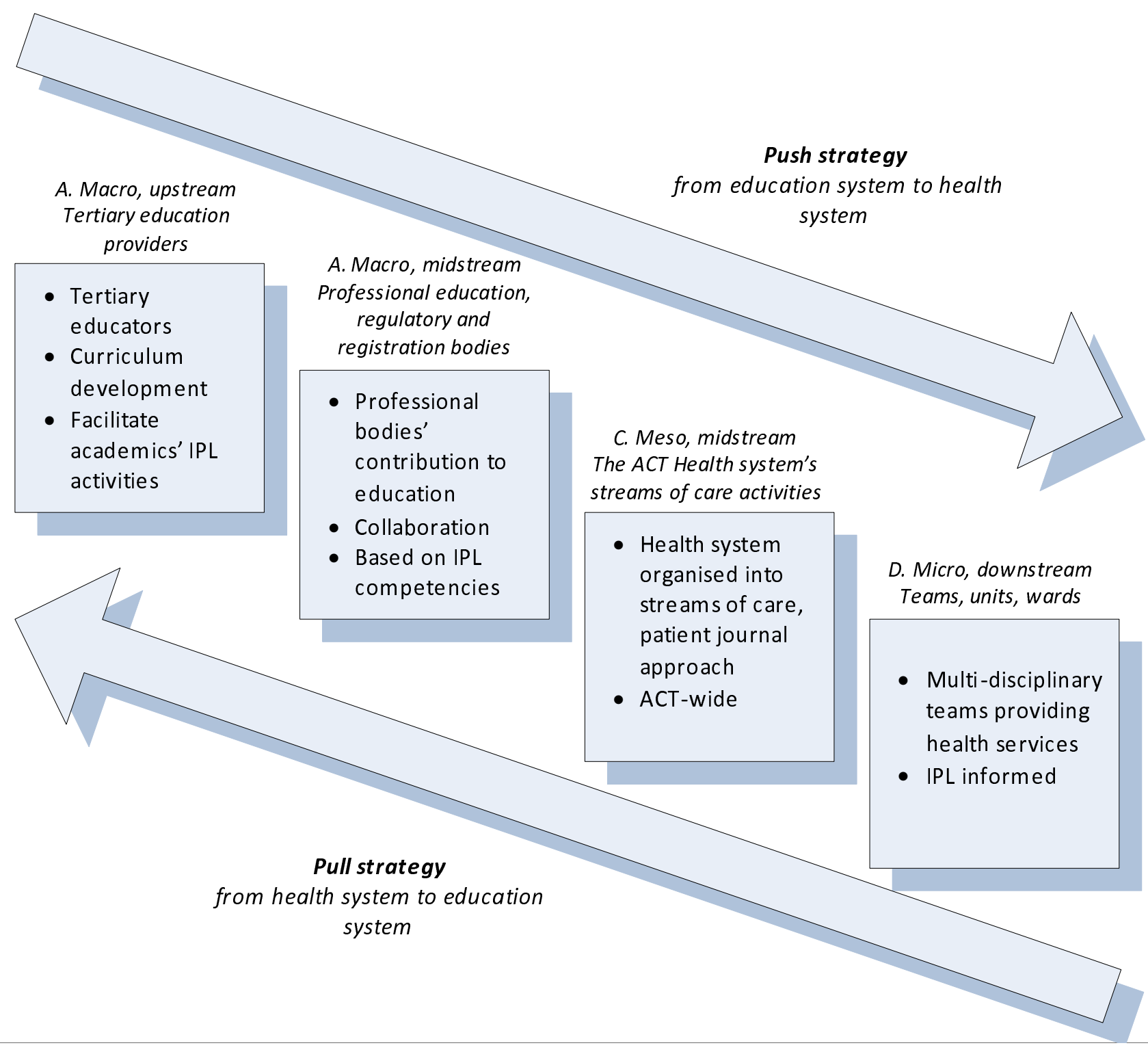

Figure I

Four areas of focus for the IPL project.

tionalise IPL in four domains: first, through major tertiary health sector education providers (eg, Australian Catholic University (ACU), Australian National University (ANU), Canberra Institute of Technology (CIT) and University of Canberra (UC); second, amongst professional education, regulatory and registration bodies (eg, Australian Physiotherapy Association (APA), Royal College of Nursing, Australia (RCNA), Royal Australian College of Physicians (RACP), Royal Australasian College of Surgeons (RACS), Royal Australian College of General Practitioners (RACGP), the regional General Practice (GP) registrar training group - CoastCityCountry Training, the Council of Pharmacy Registering Authorities (CPRA), and various ACT Registration Boards); third, via the streams of care through which ACT Health provides Territory-wide services (eg Community Health Services, Mental Health ACT, Capital Region Cancer Services, Aged Care \& Rehabilitation Service); and fourth, in teams, wards and departments that provide local services (eg, surgical, medical, emergency units).

\section{Research design}

We have designed four interrelated prospective studies to meet our aims and objectives. Our design conducts this 
research project with four components in a sustainable study: macro, upstream, involving tertiary education providers; macro, midstream, involving professional education, regulatory and registration bodies; meso, midstream, involving ACT Health's streams of care activities; and micro, downstream, involving teams, units and wards. As Figure 1 schematically argues, an action research project in the way we have conceptualised, depending on the strength of the enabling forces, can provide the push and pull needed for take up and institutionalisation of IPL and IPP.

While it is true to say that the case has been advanced since the 1960s that IPL and IPP are important, recent work including from the IOM in Health professions education: a bridge to quality [40], the report of the Pew Commis- sion [43], the Centre for Inter-professional Education and Research [44], the Higher Education Academy Health Services Practice Network [45] and various other commentators have made strong arguments underpinning the kind of research design proposed here. But research into IPL's and IPP's effectiveness has never been done before in this way, across an entire health system. An action research approach with a motivated partner organisation has much to offer, including potential for breakthrough performance gains in practice, rather than in theory, in isolated case studies, or in the laboratory. Conducting a project at four levels is challenging but is what is needed to achieve the much-vaunted but rarely realised workforce-enabled systems change. This is necessary for effective health reform and to provide a demonstration for other sectors which are in need of enhanced teamwork.

\begin{tabular}{|c|c|c|c|c|}
\hline Aims & Objectives & Methods & Phases & Outcomes \\
\hline $\begin{array}{l}\text { Enhance } \\
\text { teamwork, } \\
\text { collabor- } \\
\text { ation and } \\
\text { the sharing } \\
\text { of ideas } \\
\text { across the } \\
\text { four levels } \\
\text { of research } \\
\text { attention in } \\
\text { Figure 1: } \\
\text { A Tertiary } \\
\text { education } \\
\text { providers } \\
\text { B Profess- } \\
\text { ional bodie: } \\
\text { C Streams } \\
\text { of care, } \\
\text { ACT-wide } \\
\text { D Teams } \\
\text { within ACT } \\
\text { Health } \\
\text { facilities }\end{array}$ & $\begin{array}{l}\text { For each of the four } \\
\text { aims, meet five } \\
\text { objectives: } \\
\text { 1. Conduct an IPL and } \\
\text { IPP audit, provide } \\
\text { feedback } \\
\text { 2. Establish and } \\
\text { disseminate IPL } \\
\text { materials, train } \\
\text { stakeholders in IPL } \\
\text { and IPP } \\
\text { Facilitate } \\
\text { modifications to } \\
\text { curricula (levels A } \\
\text { and B) and learning } \\
\text { structures (levels C } \\
\text { and D) via reference } \\
\text { groups } \\
\text { Map emergent } \\
\text { successes and } \\
\text { failures in IPL } \\
\text { curricula } \\
\text { development and } \\
\text { practice } \\
\text { improvement } \\
\text { Measure field } \\
\text { progress, provide } \\
\text { feedback to each } \\
\text { stakeholder group }\end{array}$ & $\begin{array}{l}\text { Aims A-D, Obj. 1: } \\
\text { Audit and evaluate } \\
\text { the state of play at } \\
\text { project inception } \\
\text { across the project of } \\
\text { IPL and IPP using } \\
\text { Øvretveit's model[1] } \\
\text { Aims A-D, Obj. 2: } \\
\text { Compile, } \\
\text { disseminate and train } \\
\text { stakeholders in IPL } \\
\text { and IPP } \\
\text { Aims A-D, Obj. 3: } \\
\text { Facilitate } \\
\text { improvements in IPL } \\
\text { and IPP via } \\
\text { reference groups } \\
\text { Aims A-D, Obj. 4: } \\
\text { Map progress using } \\
\text { critical incident and } \\
\text { journey mapping } \\
\text { techniques } \\
\text { Aims A-D, Obj. 5: } \\
\text { Measure via focus } \\
\text { groups, a survey tool } \\
\text { and interviews; } \\
\text { provide feedback }\end{array}$ & $\begin{array}{l}\text { Year 1: Employ } \\
\text { staff; entry into } \\
\text { sites; develop } \\
\text { relationships; } \\
\text { establish audit } \\
\text { designs; create } \\
\text { tools, develop } \\
\text { educational and } \\
\text { change tools, } \\
\text { organise refer- } \\
\text { ence groups; do } \\
\text { first iteration of } \\
\text { data collection } \\
\text { and FEFLs } \\
\text { Years } 2,3 \text { and } \\
\text { 4: Map, } \\
\text { measure, } \\
\text { analyse, } \\
\text { facilitate and } \\
\text { feed back data } \\
\text { and learning } \\
\text { points } \\
\text { Year } 4 \text { : Finalise } \\
\text { project, execute } \\
\text { dissemination } \\
\text { plan, create } \\
\text { sustainable } \\
\text { outputs }\end{array}$ & $\begin{array}{l}\text { 1. Integrated push- } \\
\text { pull model tested } \\
\text { for resilience and } \\
\text { research value } \\
\text { 2. Systems-wide, } \\
\text { localised } \\
\text { collaboration and } \\
\text { team-based } \\
\text { models realised } \\
\text { 3. More flexible } \\
\text { tertiary, profess- } \\
\text { ional educational } \\
\text { offerings } \\
\text { predicated on IPL } \\
\text { 4. Various models of } \\
\text { across-ACT } \\
\text { Health streams of } \\
\text { care and within- } \\
\text { ACT Health } \\
\text { clinical wards, } \\
\text { units and } \\
\text { departments } \\
\text { examined and } \\
\text { enacted } \\
\text { 5. Measure impact } \\
\text { on IPP } \\
\text { performance on } \\
\text { clinical and } \\
\text { organisational } \\
\text { indicators. }\end{array}$ \\
\hline
\end{tabular}

\section{Figure 2}

Research approach. 
Focusing on a push-pull model, and using improvement cycles based on formative evaluation feedback loops (FEFLs, see Figure 2), have much to recommend them. Providing bi-directional feedback loops is a bespoke strategy based on our collective expertise in conducting research and evaluation projects $[46,47]$. This is research which is conceptually advanced and original, as we are testing a theoretical model never before used; our fourlevel, push-pull model has been purpose-designed for the task at hand.

\section{Aims and objectives}

Few studies illuminate research progress at four levels of a complex system, and even fewer harness the pressure of a push-pull model to try to invoke sustainable change. We are striving for an integrated strategy from education through to practice, and practice through to education, and aim to create culture change across all four levels. In systems dynamics terms this, if successful, becomes selfreinforcing. The project has four specific research aims and it will attempt to address these, and 20 research objectives, over four years; see Figure 2, Research approach.

The aims are to enhance teamwork, collaboration and the sharing of ideas, knowledge and practice amongst:

A. Educational facilities and learners in tertiary educational programs associated with ACT Health

B. Professional education, and regulatory and registration bodies providing education to their members, associated with ACT Health

\section{Clinicians in ACT Health's streams of care}

D. Teams, wards and units throughout ACT Health.

Each of the aims has five project objectives. These are as follows.

1. At project inception conduct an IPL and IPP audit of each stakeholder group in A-D above

2. Establish a repository of education-oriented IPL materials, disseminate these to partners and others involved in the project, and train stakeholder groups A-D in IPL and IPP

3. Facilitate modifications to tertiary and professional educational curricula (stakeholder groups A and B) and learning structures in streams of care and team-based units (stakeholder groups $C$ and D) through various reference groups for each of A-D at each level of the project to guide and promote curricula and practice change
4. Map emergent successes and failures in IPL and IPP progress amongst stakeholder groups A-D against curricula developments and practice changes at six months and thereafter annually using critical incident and journey mapping techniques [48] and provide feedback to participants using FEFL strategies to encourage further IPL and IPP improvements

5. Measure progress via focus groups, questionnaire survey administration and key stakeholder interviews at predetermined marker times - at nine months, one year nine months, two years nine months and three years nine months of the project and provide feedback to stakeholder groups A-D using FEFLs to encourage further IPL and IPP improvements.

The project will examine IPL and IPP processes in the Territory at the project's inception and as it unfolds, and gather baseline and ongoing data to measure project progress. It will enhance take-up through the FEFL strategy. These data will provide an evidence base for ongoing project enhancements.

\section{Research plan}

Figure 3 shows how the project will play out in a detailed research plan and process. This builds on the collaborative partnership, action research ideals of the research design.

\section{Discussion}

\section{IPL and IPP as cornerstones of health care reform}

IPL and IPP are increasingly seen as building blocks to progress in health care. The ageing workforce [49], projected shortages of staff [50], problematic morale because of isolated groups and autonomy [51] and disaffection with existing fragmented health services [52] are seen by the Australian Productivity Commission [53], amongst others, to be in need of attention. We have worked throughout 2005 and 2006 in a partnership involving jointly-conducted meetings, reference group sessions, workshops, seminars, consultancy processes and networkbuilding underpinned by an extended literature review [10] and discussion documents $[11,54,55,56]$ which have been circulated throughout ACT Health. We designed an IPL framework [16] and implementation plan [57] to underpin IPL's institutionalisation throughout the ACT health and associated education systems. The main tertiary health education providers at ACU, ANU, CIT and UC are committed to this project and have confirmed their willingness and capacity to engender flexibility in educational offerings. We have secured high-level endorsement for this project and recognition of its importance from the Minister for Health in the ACT Government, the Director-General of Health for the ACT and the Commissioner who led the recent Productivity Commis- 


\begin{tabular}{|c|c|c|c|c|c|c|c|c|c|c|c|c|}
\hline \multirow[b]{2}{*}{ Activity } & \multicolumn{12}{|c|}{ Months } \\
\hline & 1 & 2 & 3 & 4 & 5 & 6 & 7 & 8 & 9 & $\mathbf{1}$ & $\begin{array}{l}1 \\
1\end{array}$ & 1 \\
\hline \multicolumn{13}{|l|}{2007} \\
\hline Ethics/ Recruitment/ Finalisation of initial data collection tools, protocols & - & - & - & & & & & & & & & \\
\hline Data reports to partners and stakeholders, steering committee meetings & & - & & & - & & & - & & & - & \\
\hline Reference group formation, consultations and meetings & - & - & - & & & - & & & - & & & - \\
\hline Create audit designs, research tactics, collaborative structures & - & - & - & - & - & - & & & & & & \\
\hline Train stakeholder groups & - & - & - & - & - & - & & & & & & \\
\hline First iteration of data (mapping successes, failures, providing feedback) & & & & & & - & - & - & - & & & \\
\hline First iteration of data (measuring progress, providing feedback) & & & & & & & & & - & - & - & - \\
\hline \multicolumn{13}{|l|}{2008} \\
\hline Reference group, steering committee preparation, consultation processes & - & - & & & & & & & & & & \\
\hline Data analysis, reports to partners and stakeholders & + & & & - & & & - & & & - & & \\
\hline Steering committee meetings & & - & & & + & & & - & & & - & \\
\hline Reference group consultations and meetings & & & - & & & - & & & - & & & - \\
\hline Mapping successes and failures, providing feedback, conducting FEFLs & & & & & & - & - & - & - & & & \\
\hline Measuring progress, providing feedback, conducting FEFLs & & & & & & & & & 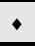 & - & - & - \\
\hline \multicolumn{13}{|l|}{2009} \\
\hline Reference group, steering committee preparation, consultation processes & - & - & & & & & & & & & & \\
\hline Data analysis, reports to partners and stakeholders & - & & & - & & & - & & & - & & \\
\hline Steering committee meetings & & - & & & - & & & - & & & - & \\
\hline Reference group consultations and meetings & & & - & & & - & & & - & & & - \\
\hline Mapping successes and failures, providing feedback, conducting FEFLs & & & & & & - & - & - & - & & & \\
\hline Measuring progress, providing feedback, conducting FEFLs & & & & & & & & & - & - & - & - \\
\hline \multicolumn{13}{|l|}{2010} \\
\hline Reference group, steering committee preparation, consultation processes & - & - & & & & & & & & & & \\
\hline Data analysis, reports to partners and stakeholders & - & & & - & & & - & & & - & & \\
\hline Steering committee meetings & & - & & & - & & & - & & & - & \\
\hline Reference group consultations and meetings & & & - & & & - & & & - & & & - \\
\hline Mapping successes and failures, providing feedback, conducting FEFLs & & & & & & - & - & - & - & & & \\
\hline Measuring progress, providing feedback, conducting FEFLs & & & & & & & & & - & - & - & - \\
\hline Performance analysis and review & & & & & - & - & - & - & - & & & \\
\hline Preparation of publications, presentations to staff at study sites & & & & & & & & - & - & - & - & - \\
\hline
\end{tabular}

Figure 3

Detailed research plan and process.

sion inquiry which culminated in the report Australia's health workforce [53], a major reform document. Additionally, the project drew on the other advanced international work in this field [58].

\section{The benefits of multi-method, partnership research}

Projects of this type are essentially measuring progress formatively, invoking capacity-building measures and attempting to build substantial research assets for the future. The partners enabling these research aims to be met have co-designed the ACT Health's IPL initiative and the action research project specified here. Success is dependent on strong partnerships and robust relationships.

ACT Health is a highly motivated partner and has been an instrumental participant in the development of the study. Staff across the ACT have participated in a reference group last year $[n=65]$, and consultations have been conducted about this project with approximately 200 staff members. ACT Health and the ARC project investigators and other partners have facilitated discussions with a wide range of stakeholder groups at the four levels identified in Figure 1. The partners have also conducted in late 2006 an Aus- 
tralia-wide inter-jurisdictional workshop for educational providers, regulators, registration bodies and practitioners. Senior policy, managerial and clinical staff have been involved in the detailed research design developments and several staff members are beginning the process of enrolling in a PhD in the topic area. Many ACT Health staff are keen to be involved in the studies and are willing to commit time as an adjunct to their usual workload. They have a range of experiences and expertise that will provide critical knowledge to the studies.

ACT Health's Health action plan, its primary document setting strategic directions, advocates a considered approach to health status improvement for the Territory's residents, calling, inter alia, for healthy systems - building a sustainable workforce, integrating hospital and community health services and enhancing the quality of health and community services. Although IPL and IPP underpin the various components of the Health action plan's proposals, nevertheless it contributes particularly strongly to these three aspects.

The project is valuable to ACT Health in numerous ways, as the foregoing articulates. If we can achieve our aims and realise this project's contributions we will have enabled major team-based, IPP-oriented improvements. Even if we make only modest or uneven progress we stand to create a platform for improvement, underpinning future initiatives designed to create sustained systems change. These are goals worth pursuing.

In essence, the research aims and objectives posed require a multi-method [59], multi-level approach [60] which incorporates both qualitative and quantitative data [61]. The research program investigates performance in terms of empirical data, what people say occurs (focus groups, interviews and survey questionnaires) and observations of what occurs (critical incident mapping, reference group experiences and field observations). A wide range of evaluation techniques will thus be applied in meeting the study aims and objectives. This is thus innovative research of high strategic value.

\section{Closing the loop by communicating results}

We have designed multiple strategies by which to communicate results. Too often formative results of large-scale research projects lie dormant or are unpublished. First, we are in the process of establishing a website to facilitate dissemination of our findings and lessons learnt, targeted to our partners and stakeholders as well as other interested parties nationally and internationally. Second, we are keen to diffuse results. We will do this via conference, symposia and workshop presentations and academic journals. Third, we are beginning to target multiple external stakeholders who are interested in the findings and their implications. To do this we intend designing useful summaries for the benefit of interested parties. Whenever we have done this previously we have been struck by the way this is warmly received. Fourth, we are motivated to share our experiences with the multi-method research model at the heart of this project. In testing a publiclyfunded multi-method model and investigating how this works there is a moral imperative to share this with other researchers and practitioners.

Most important is the research translational competencies we intend applying to this project. We seek to go beyond communications of results; this project itself is based on an action research model but collectively we are committed to translational research. We have involved a very wide range of partners and stakeholders and secured their expertise, engaged them and sought their active involvement to develop the research protocol. We plan to conduct media interviews and public lectures about how our results fit into health sector reform as they emerge, and how to improve the way in which professionals work together. We are also arranging to give lectures to senior high school students to influence their career choices and prepare them for inter-professional learning and practice when they go into the workforce.

\section{Conclusion}

Systems-wide, empirical evidence about IPL and IPP is sparse. We seek to redress this deficit in part via this largescale project. A research design predicated on multimethod, multi-disciplinary, multi-level collaborative principles is one that is likely to reflect the complexity of the issues to be investigated. In disseminating this research protocol through open access we aim to generate debate about the possibilities of success, to generate feedback from colleagues, and to create a dialogue with other interested researchers in this area.

\section{Abbreviations}

ACT, Australian Capital Territory; ACT Health, the Australian Capital Territory health service provider; ACU, Australian Catholic University; AGSM, Australian Graduate School of Management; ANU, Australian National University; APA, Australian Physiotherapy Association; ARC, Australian Research Council; CCGR, Centre for Clinical Governance Research at University of New South Wales; CIT, Canberra Institute of Technology; CPRA, Council of Pharmacy Registering Authorities; FEFL, Formative Evaluation Feedback Loop; FTE, Full-Time Equivalent; GP, General Practice; IOM, Institute of Medicine, United States of America; IPE, Inter-professional education; IPL, Inter-professional learning; IPP, Inter-professional practice; NHS, National Health Service; RACGP, Royal Australian College of General Practitioners; RACP, Royal Australasian College of Physicians; RACS, Royal 
Australasian College of Surgeons; RCNA, Royal College of Nursing, Australia; UC, University of Canberra

\section{Competing interests}

This research is supported under the Australian Research Council's Linkage Projects funding scheme [project number LP0775514] which brings together industry partners [represented by KM] and academics [led by JB] to undertake partnership research. While no-one reports any financial or non-financial competing interests, these kinds of research partnerships require the development of appropriate safeguards, including a clear understanding of roles, responsibilities and the arm's length nature of academic researchers. There is an acceptance of the collaborators that results may differ from their expectations and be disadvantageous to their interests, but nevertheless publication will be pursued.

\section{Authors' contributions}

$\mathrm{JB}, \mathrm{JW}, \mathrm{ARF}, \mathrm{RB}, \mathrm{TD}$ and $\mathrm{MB}$ are chief investigators on the grant and made substantial contributions to the conception and design of the project and this manuscript. KM and M-AR are industry partner investigators, as was JBe at the time of the development of the protocol. RV, ER, JT, JS, $\mathrm{AB}, \mathrm{DG}, \mathrm{AC}, \mathrm{PN}$ and $\mathrm{RC}-\mathrm{W}$ contributed at various times to the project's conceptualisation, as members of one of the steering committees or are involved in one or more components of the research studies. All authors contributed to this project and the paper and read, and approved, the final manuscript.

\section{Acknowledgements}

Sources of funding: JB, JW, ARF, RB, TD, RV, JT, AB, DG, AC, PN and RC$W$ are academics, remunerated primarily by their respective universities. $M B, K M, M-A R, J B e$ [at the time of the development of the protocol], ER and JS are remunerated primarily via ACT Health. The funding bodies had no role in the study design; collection, analysis or interpretation of data; the writing of this manuscript; and the decision to submit the manuscript for publication. Ethics approvals for the research has been granted by the UNSW Human Research Ethics Committee [HREC 07002(PI)/Panel Ref 903-8I on 20 February 2007] and the ACT Health Human Research Ethics Committee [ETH.3/07.274 on 2 April 2007].

\section{References}

I. Øvretveit J: Action evaluation of health programmes and changes: a handbook for a user-focused approach. Oxford: Radcliffe Medical Press; 2002.

2. Kvarnström S, Cedersund E: Discursive patterns in multiprofessional healthcare teams. J Adv Nurs 2006, 53(2):244-252.

3. Stout R, Salas E: The role of trainee knowledge structures in aviation team environments. Int J Aviat Psychol 1997, 7(3):235-250.

4. Coupland $C$, Blyton $P$, Bacon N: A longitudinal study of the influence of shop floor work teams on expressions of 'us' and 'them'. Hum Relat 2005, 58(8): I055-108I.

5. McKee T: Building successful teams in the midst of transition. J Qual Part 2003, 26(I):43.

6. Bleakley A: Broadening conceptions of learning in medical education: the message from teamworking. Med Educ 2006, 40(2): $150-157$.
7. Wright MC, Kaber DB: Effects of automation of informationprocessing functions on teamwork. Hum Factors 2005, 47(I):50-66.

8. Department of Health: The Report of the Public Enquiry into children's heart surgery at the Bristol Royal Infirmary I9841995: learning from Bristol. London: The Stationary Office; 200 I.

9. Douglas N, Robinson J, Fahy K: Inquiry into obstetric and gynaecological services at King Edward Memorial Hospital I9902000. Perth: Government of Western Australia; 200 I.

10. Braithwaite J, Travaglia J: Inter-professional learning and clinical education: an overview of the literature. Canberra: ACT Health Department; 2005: I-59.

II. Braithwaite J, Travaglia J: The ACT Health inter-professional learning and clinical education project: discussion paper \#3 [inter-professional relations]. Canberra: ACT Health Department; 2005:1-17.

12. Barr H: Competent to collaborate: towards a competencybased model for interprofessional education. J Interprof Care 1998, I 2(2): 181-188.

13. Castro RM, Julia MC: Interprofessional care and collaborative practice. Pacific Grove: Brooks - Cole Publishing Company; 1994.

14. Arredondo P, Shealy C, Neale M, Winfrey LL: Consultation and interprofessional collaboration: modeling for the future. J Clin Psychol 2004, 60(7):787-800.

15. Barr H: Partnership or pretence? J Interprof Care 2004, I 8(2): $101-102$.

16. Braithwaite J, Travaglia J: A framework for inter-professional learning and clinical education for ACT Health. Canberra: ACT Health Department; 2006: I-I8.

17. Oandasan I, Reeves S: Key elements in interdisciplinary education. In Interdisciplinary education for collaborative, patient-centred practice: research and findings report Edited by: Oandasan I, D'Amour D, Zwarenstein M, Barker K, Purden M, Beaulieu MD, Reeves S, Nasmith L, Bosco B, Ginsburg L, et al. Ottawa: Health Canada; 2004.

18. Engeström $\mathrm{Y}$, Engeström R, Kerosuo H: The discursive construction of collaborative care. Appl Linguist 2003, 24(3):286-3 I 5.

19. Hughes JL, Hemingway S, Smith AG: Interprofessional education: nursing and occupational therapy - could old rivals integrate? Nurse Educ Pract 2005, 5(I): 10-20.

20. Atwal A, Caldwell K: Do multidisciplinary integrated care pathways improve interprofessional collaboration? Scand J Caring Sci 2002, I 6(4):360-367.

21. Sexton JB, Thomas EJ, Helmreich RL: Error, stress, and teamwork in medicine and aviation: Cross sectional surveys. $\mathrm{Br}$ Med J 2000, 320:745-749.

22. Phillips RL Jr, Harper DC, Wakefield M, Green LA, Fryer GE Jr: Can nurse practitioners and physicians beat parochialism into plowshares? A collaborative, integrated health care workforce could improve patient care. Health Aff 2002, 2 I(5): | 33-142.

23. Antunez HG, Steinmann WC, Marten L, Escarfuller J: A multidisciplinary, culturally diverse approach to training health professions students. Med Educ 2003, 37( I 0):921.

24. Rudland JR, Mires GJ: Characteristics of doctors and nurses as perceived by students entering medical school: Implications for shared teaching. Med Educ 2005, 39(5):448-455.

25. Tucker K, Wakefield A, Boggis C, Lawson M, Roberts T, Gooch J: Learning together: clinical skills teaching for medical and nursing students. Med Educ 2003, 37(7):630-637.

26. Mandy A, Milton C, Mandy P: Professional stereotyping and interprofessional education. Learn Health Soc Care 2004, 3(3): I54- 170.

27. Finch J: Interprofessional education and teamworking: a view from the educational provider. Br Med J 2000, 32 I: I I38-I I 40.

28. Barker KK, Bosco C, Oandasan IF: Factors in implementing interprofessional education and collaborative practice initiatives: Findings from key informant interviews. J Interprof Care 2005, I 9(SUPPL I): I66-176.

29. Barr H: Cochrane review of outcomes from interprofessional education. Educ Health 1998, I I (3):402-403.

30. Zwarenstein M, Atkins J, Barr H, Hammick R, Koppel I, Reeves S: A systematic review of interprofessional education. J Interprof Care 1999, I3(4):417-424.

31. Zwarenstein M, Bryant W: Interventions to promote collaboration between nurses and doctors. Cochrane Database Syst Rev 2000:CD000072. 
32. Zwarenstein M, Reeves S, Barr H, Hammick M, Koppel I, Atkins J: Interprofessional education: effects on professional practice and health care outcomes. Cochrane Database Syst Rev 200I:CD0022I3.

33. Kohn L, Corrigan J, Donaldon M, (eds): To err is human: building a safer health system. Washington, D.C.: National Academy Press; 1999.

34. Final Report of the Special Commission of Inquiry into Campbelltown and Camden Hospitals - 30 July 2004 [http:// www.lawlink.nsw.gov.au/special commission]

35. Forster AJ, Clark HD, Menard A, Dupuis N, Chernish R, Chandok N, Khan $A$, van Walraven C: Adverse events among medical patients after discharge from hospital. CMAJ 2004, I 70(3):345-349.

36. Institute of Medicine: Crossing the quality chasm: a new health system for the 2 Ist century. Washington: National Academy Press; 2001.

37. Runciman B, Merry A, Walton M: Safety and ethics in healthcare: a guide to getting it right. Aldershot: Ashgate; 2007.

38. Braithwaite J: Hunter-gatherer human nature and health system safety: An evolutionary cleft stick? Int J Qual Health Care 2005, I7(6):54I-545.

39. Health Workforce Advisory Committee: The New Zealand health workforce future directions - recommendations to the Minister of Health. Wellington, NZ: HWAC; 2003.

40. Institute of Medicine: Health professions education: a bridge to quality. Washington: National Academy Press; 2003.

4I. Romanow RJ: Building on values: the future of healthcare in Canada - final report. Saskatoon: Commission on the Future of Healthcare in Canada; 2002.

42. Department of Health: Working together - learning together. A framework for lifelong learning for the NHS. London: NHS Department of Health; 200I.

43. O'Neil EH, Pew Health Professions Commission: Recreating health professional practice for a new century. San Francisco, Ca.: Pew Health Professions Commission; 1998.

44. Centre for the Advancement of Interprofessional Education: Interprofessional education: a definition. London: UK Centre for the Advancement of Interprofessional Education; 1997.

45. Freeth $\mathrm{D}$, Fry $\mathrm{H}$ : Nursing students' and tutors' perceptions of learning and teaching in a clinical skills centre. Nurse Educ Today 2005, 25(4):272-282.

46. Braithwaite J, Westbrook JI, Pawsey M, Greenfield D, Naylor J, ledema RA, Runciman B, Redman S, Jorm C, Robinson M, et al.: A prospective, multi-method, multi-disciplinary, multi-level, collaborative, social-organisational design for researching health sector accreditation [LP0560737]. BMC Health Serv Res 2006, 6: II3-123.

47. Braithwaite J, Travaglia J, Mallock N, ledema R, Westbrook M, Long $D$, Nugus $P$, Forsyth R, Jorm C, Pawsey M: Evaluation of the patient safety program in New South Wales: overview of studies. Sydney: Centre for Clinical Governance Research, University of New South Wales; 2005: I-38.

48. Westbrook J, Coeria E, Gosling A, Braithwaite J: Critical incidents and journey mapping as techniques to evaluate the impact of online evidence retrieval systems on health care delivery and patient outcomes. Int J Med Inform 2006, 76(2-3):234-245.

49. Basu K, Kingma M, Pong RW, Martinez-Carretero JM, Danon-Hersch N, Frisack J, Oberg K: The Barcelona International Symposium (2I-23 April 2005). Synthesis reports. Cah Sociol Demogr Med 2005, 45(2-3):327-364.

50. Martineau T, Willetts A: The health workforce: managing the crisis ethical international recruitment of health professionals: will codes of practice protect developing country health systems? Health Policy 2006, 75(3):358-367.

51. Gerber DR, Parrillo JE, Bekes CE: The future of hospital economic health. Crit Care Med 2006, 34(3 Suppl):S88-93.

52. Berger KW: Integrated patient management? Nurs Manage 2006, 37(I):36-40.

53. Productivity Commission: Australia's Health Workforce. Canberra: Australian Productivity Commission; 2005.

54. Braithwaite J, Travaglia J: The ACT Health inter-professional learning and clinical education project: discussion paper \#I [governance of IPL]. Canberra: ACT Health Department; 2005:1-19.
55. Braithwaite J, Travaglia J: The ACT Health inter-professional learning and clinical education project: discussion paper \#2 [inter-professional practice]. Canberra: ACT Health Department; 2005: I-16.

56. Braithwaite J, Travaglia J: The ACT Health inter-professional learning and clinical education project: discussion paper \#4 [clinical education placements]. Canberra: ACT Health Department; 2005: I-I5.

57. Braithwaite J, Travaglia J: An implementation plan for inter-professional learning and clinical education for ACT Health. Canberra: ACT Health Department; 2005:I-25.

58. Humphris D, Hean S: Educating the future workforce: building the evidence about interprofessional learning. J Health Serv Res Policy 2004, 9(Supplement I:S I):24-27.

59. Campbell CP: Instructional materials: their preparation and evaluation. J Eur Ind Train 1999, 23(2):57-107.

60. Kleinberg J: Navigation in a small world. Nature 2000, 406:845

61. Fink A: Evaluation fundamentals: guiding health programs, research and health policy. Newbury Park: Sage; 1993.

\section{Pre-publication history}

The pre-publication history for this paper can be accessed here:

\section{http://www.biomedcentral.com/1472-6963/7/144/pre} pub
Publish with Bio Med Central and every scientist can read your work free of charge

"BioMed Central will be the most significant development for disseminating the results of biomedical research in our lifetime. "

Sir Paul Nurse, Cancer Research UK

Your research papers will be:

- available free of charge to the entire biomedical community

- peer reviewed and published immediately upon acceptance

- cited in PubMed and archived on PubMed Central

- yours - you keep the copyright
BiolMedcentral 